\title{
Distinctive Viewpoint on the Rapid Dissolution Mechanism of $\alpha$-Chitin in Aqueous Potassium Hydroxide-Urea Solution at Low Temperatures
}

\author{
Junchao Huang, ${ }^{\S, \ddagger}$ Yi Zhong, ${ }^{\S, \ddagger}$ Lina Zhang, ${ }^{\ddagger, \dagger}$ and Jie Cai*,,,† \\ ‡ College of Chemistry and Molecular Sciences, Wuhan University, Wuhan 430072, China \\ ${ }^{\dagger}$ Hubei Engineering Center of Natural Polymer-based Medical Materials, Wuhan University, Wuhan \\ 430072, China
}



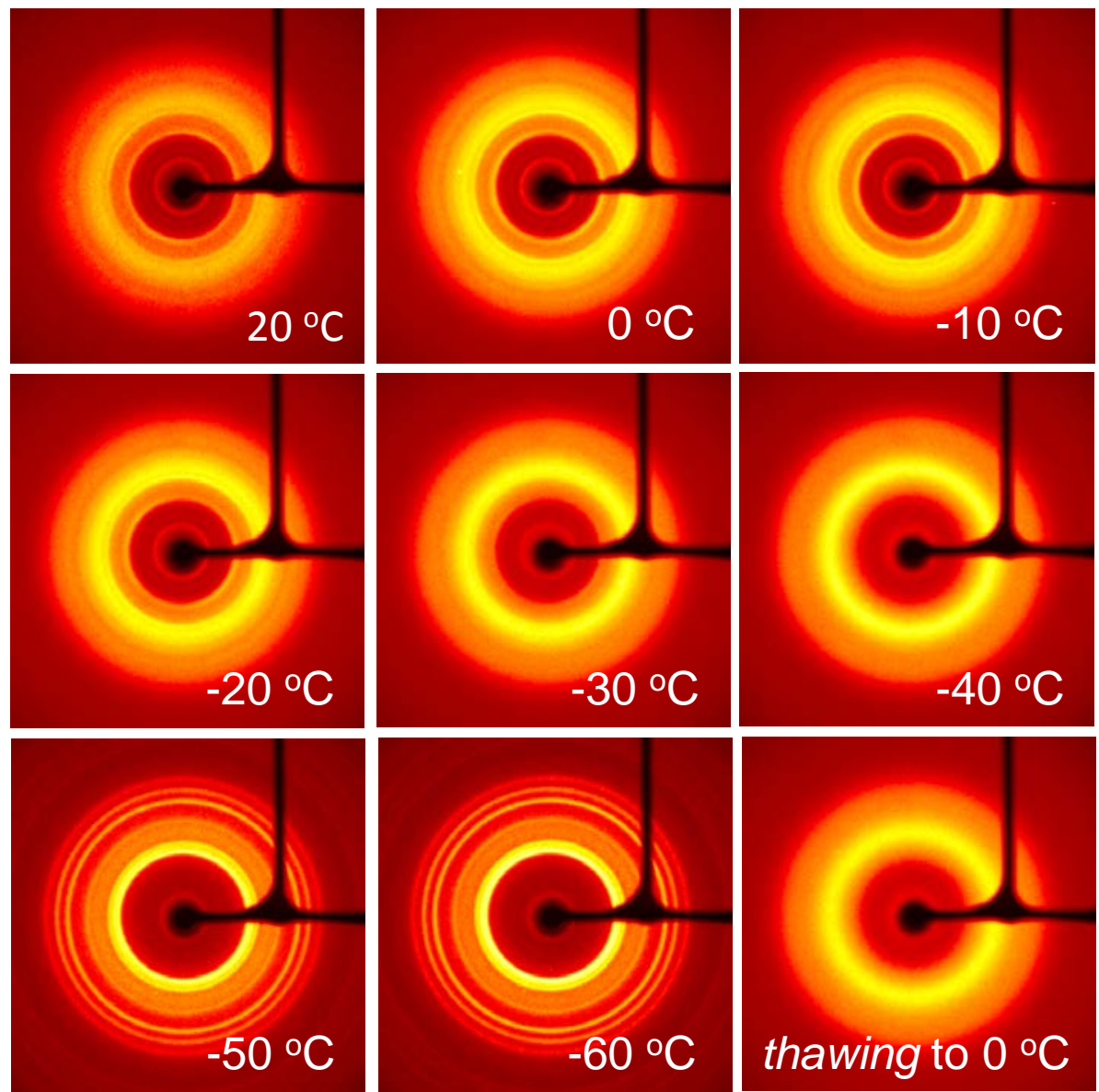

Figure S1. 2D WAXD patterns of $\alpha$-chitin dissolved in 20 wt.\% (3.6 M) aqueous $\mathrm{KOH}$ solution at different temperatures. 

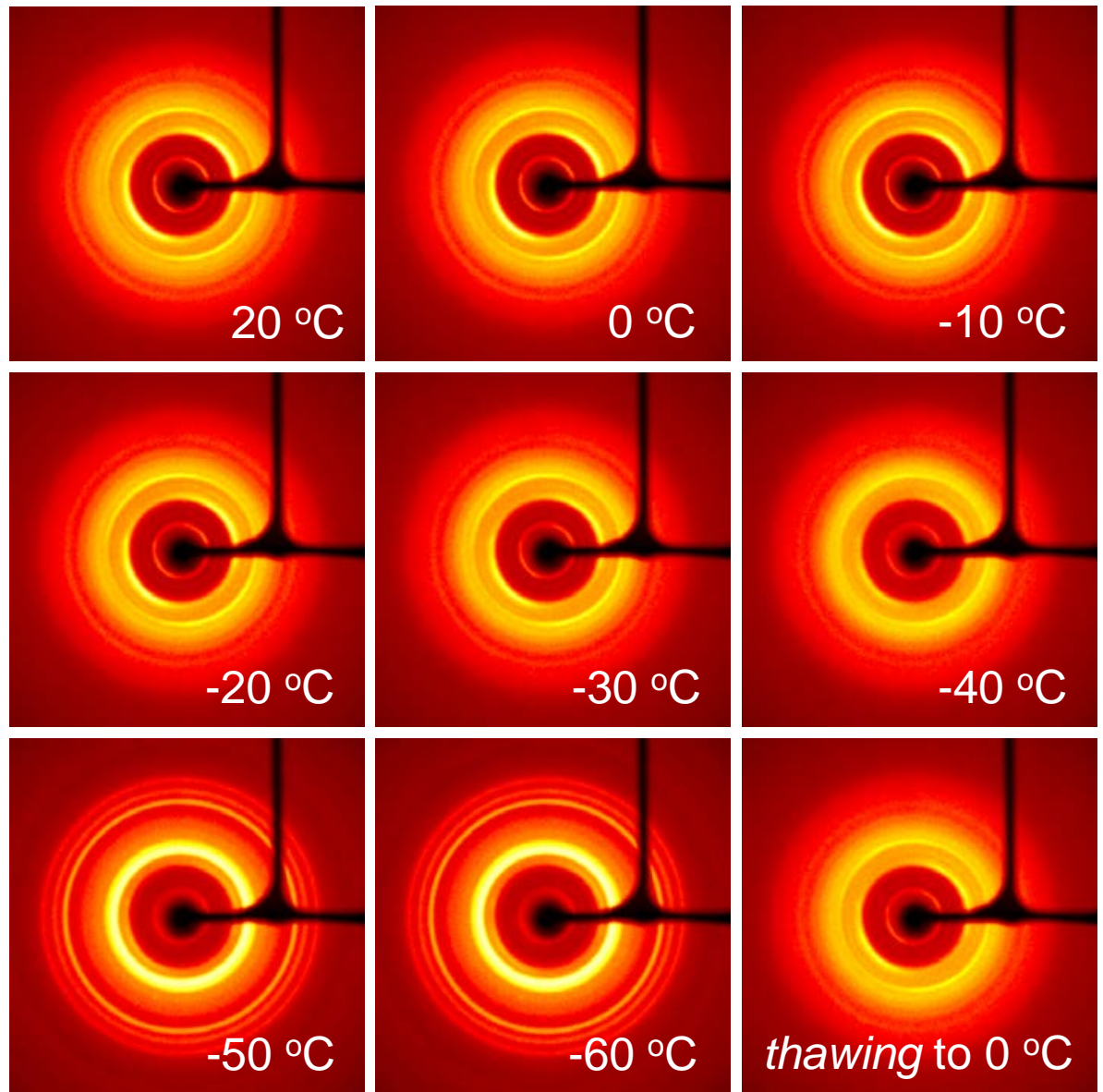

Figure S2. 2D WAXD patterns of $\alpha$-chitin powder in 14.4 wt.\% (3.6 M) aqueous $\mathrm{NaOH}$ solution at different temperatures. 

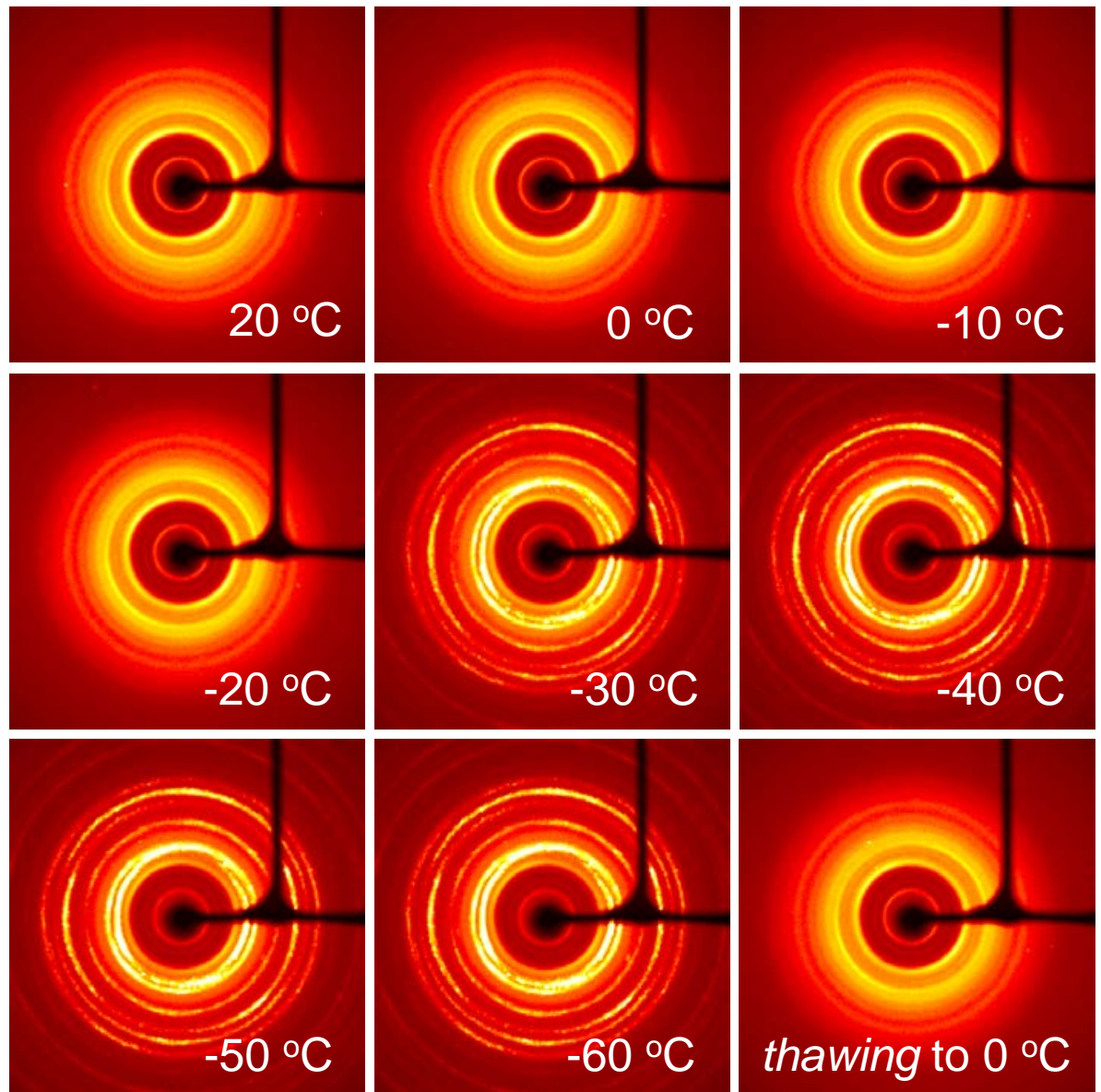

Figure S3. 2D WAXD patterns of $\alpha$-chitin powder in 8.6 wt.\% (3.6 M) aqueous $\mathrm{LiOH}$ solution at different temperatures. 

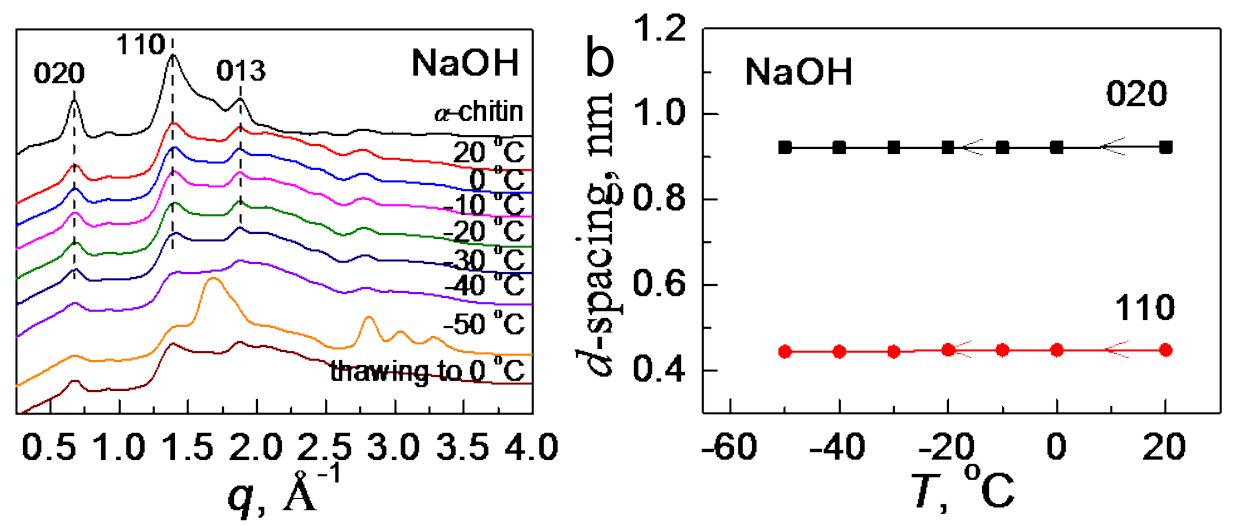

Figure S4. (a) Equatorial XRD profiles of $\alpha$-chitin powder and $\alpha$-chitin in the aqueous $\mathrm{NaOH}$ solution obtained during cooling from 20 to $-50{ }^{\circ} \mathrm{C}$ and then thawing to $0{ }^{\circ} \mathrm{C}$.

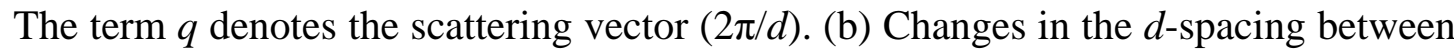
the (020) and (110) planes during cooling the aqueous $\mathrm{NaOH}$ solutions from 20 to $50{ }^{\circ} \mathrm{C}$ calculated from the XRD profiles. 


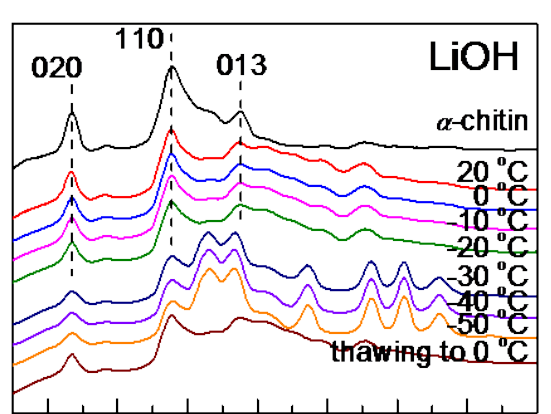

0.51 .01 .52 .02 .53 .03 .54 .0 $q, \AA^{-1}$

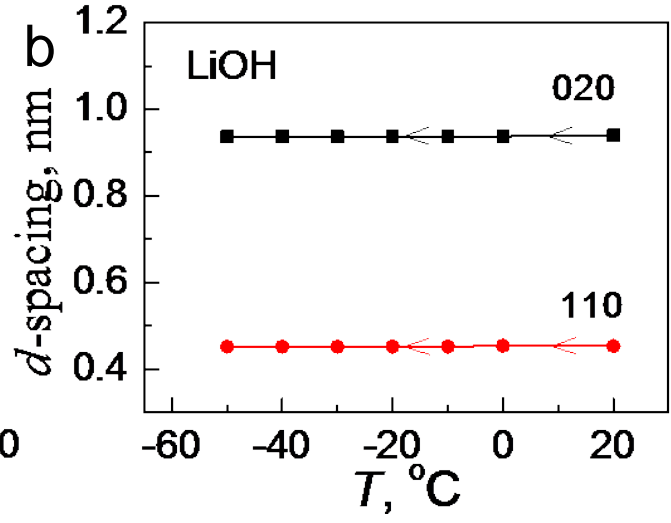

Figure S5. (a) Equatorial XRD profiles of $\alpha$-chitin powder and $\alpha$-chitin in the aqueous LiOH solution obtained during cooling from 20 to $-50{ }^{\circ} \mathrm{C}$ and then thawing to $0{ }^{\circ} \mathrm{C}$.

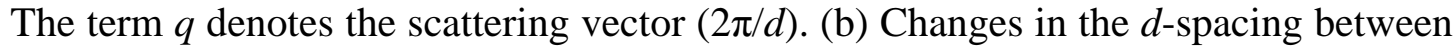
the (020) and (110) planes during cooling the aqueous $\mathrm{LiOH}$ solution from 20 to $-50^{\circ} \mathrm{C}$ calculated from the XRD profiles. 


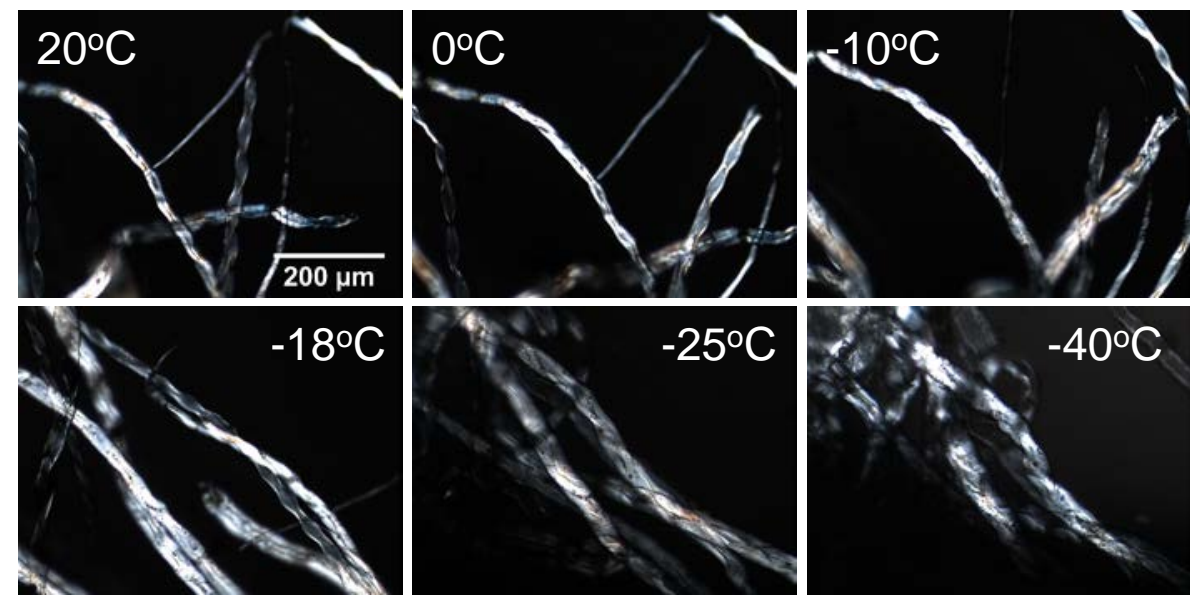

Figure S6. Polarizing microscopy images of cellulose I in the aqueous $\mathrm{KOH}$ aqueous solution at different temperatures. 

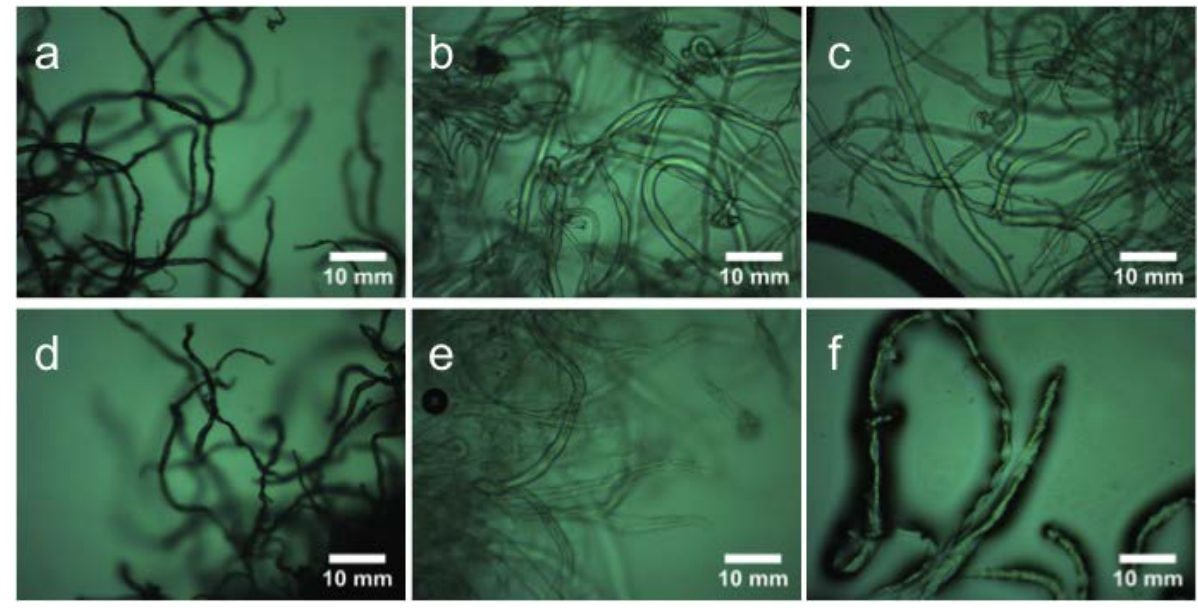

Figure S7. (a-c) Optical microscopy images of cellulose I (a), cellulose I in the aqueous $\mathrm{KOH}$ solution at $-30{ }^{\circ} \mathrm{C}$ for $30 \mathrm{~min}$ (b) and $90 \mathrm{~min}$ (c). (d-f) Optical microscope images of cellulose II (d), and cellulose II in the aqueous $\mathrm{KOH}$ solution at $-30{ }^{\circ} \mathrm{C}$ for $30 \mathrm{~min}$ (e) and $90 \min (f)$. 

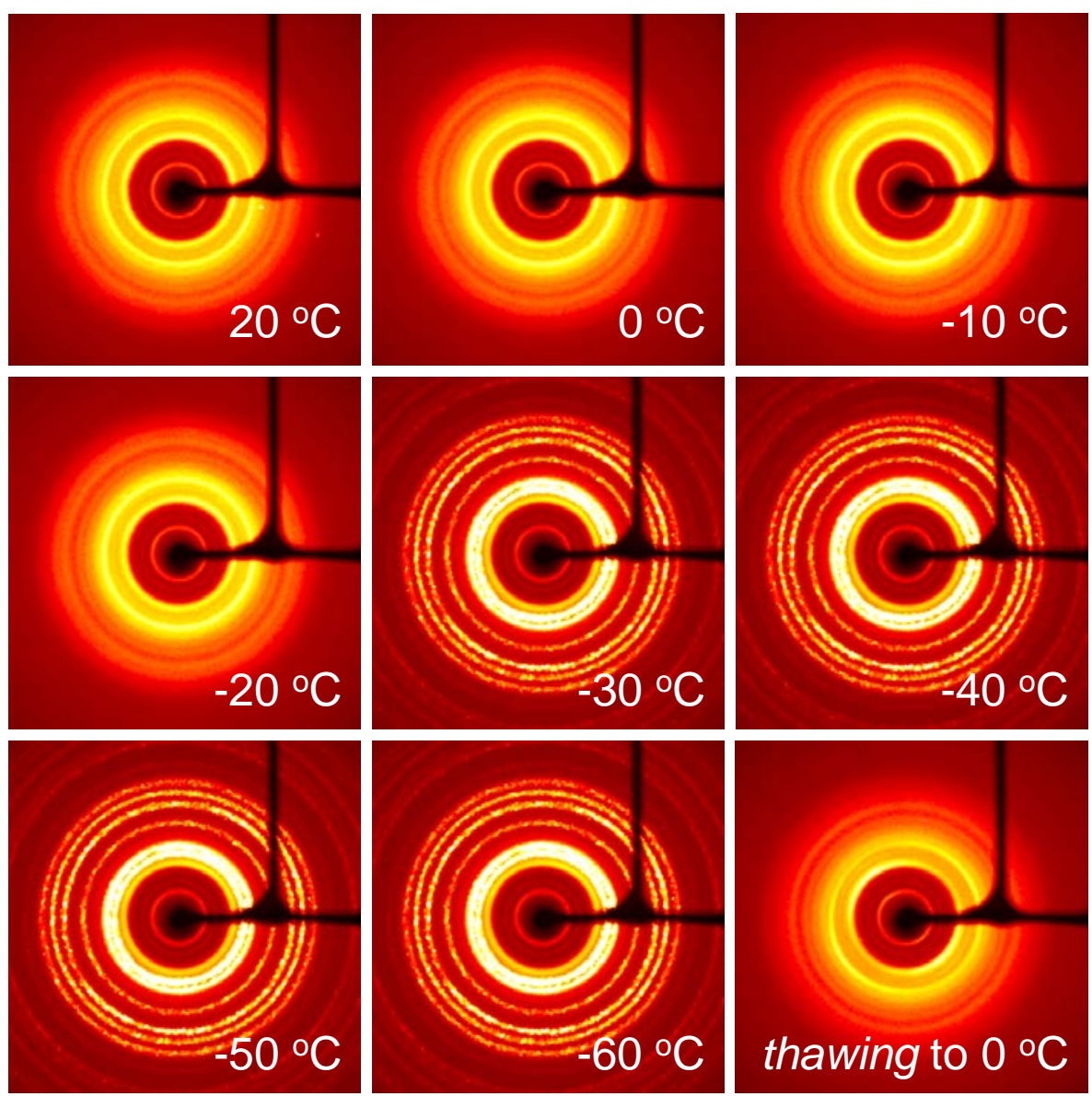

Figure S8. 2D WAXD patterns of $\alpha$-chitin powder in $4 \mathrm{wt}$.\% aqueous urea solution at different temperatures. 


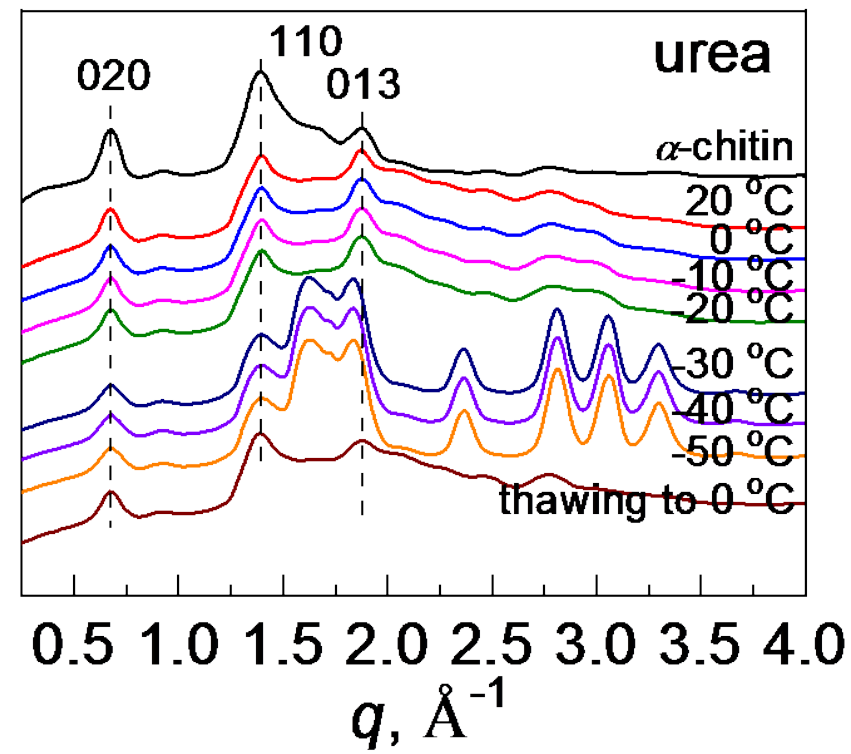

Figure S9. Azimuthal averaging XRD profiles of $\alpha$-chitin powder and $\alpha$-chitin in the aqueous urea solution during cooling from 20 to $-50{ }^{\circ} \mathrm{C}$ and then thawing to $0{ }^{\circ} \mathrm{C}$. The term $q$ denotes the scattering vector $(2 \pi / d)$. 

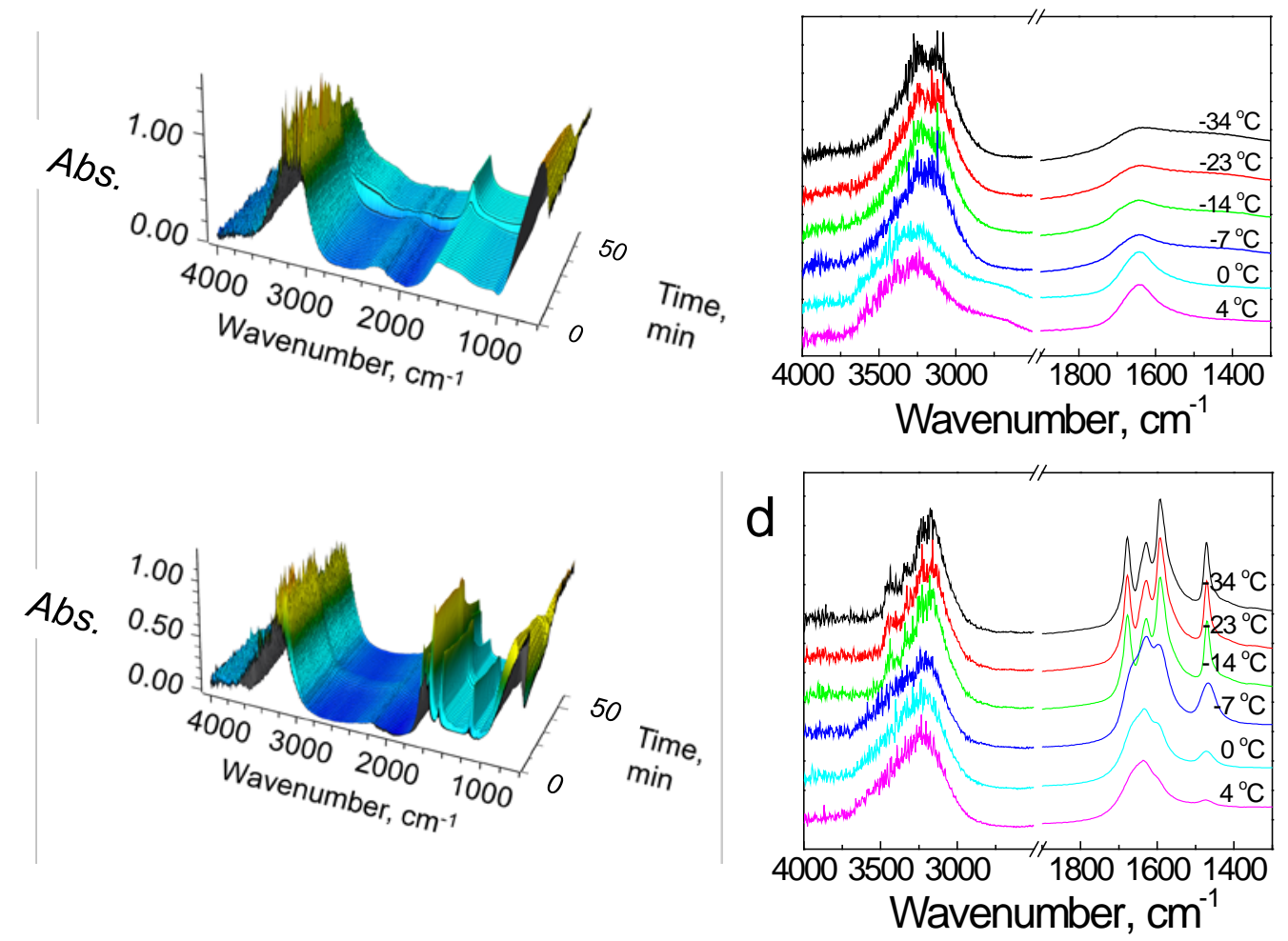

Figure S10. 3D FT-IR spectra of the $\mathrm{KOH} \mathrm{(a)} \mathrm{and} \mathrm{urea} \mathrm{(b)} \mathrm{aqueous} \mathrm{solutions} \mathrm{obtained}$ by conducting time-course measurements. FT-IR spectra of the $\mathrm{KOH}$ (c) and urea (d) aqueous solutions extracted from the 3D FT-IR spectra recorded at different temperatures. 

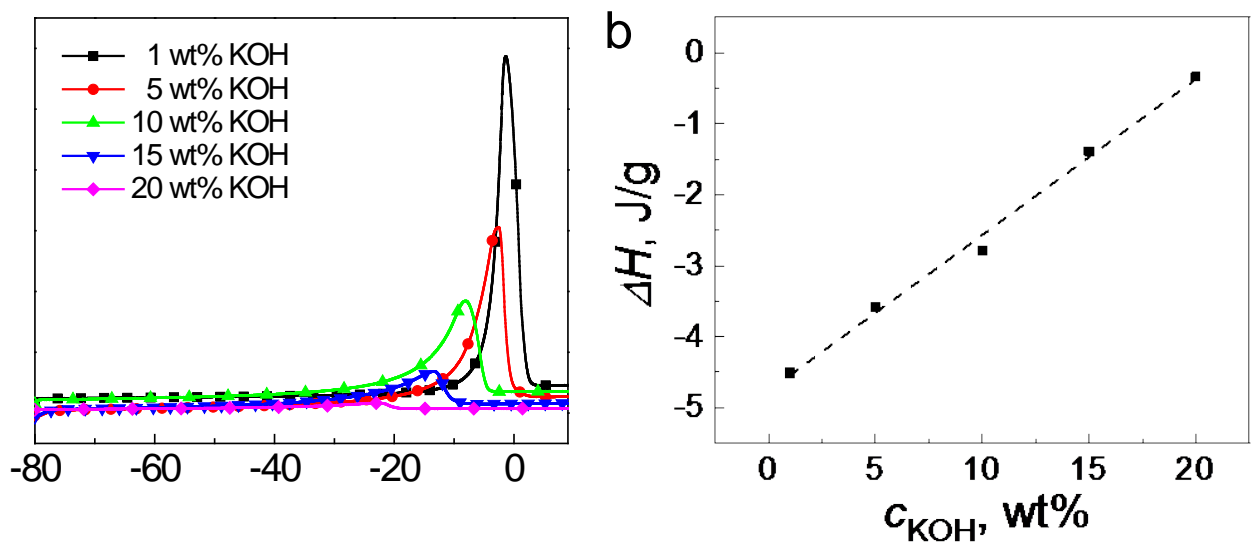

Figure S11. (a) DSC thermograms of aqueous $\mathrm{KOH}$ solutions with different concentrations. (b) Dependence of the enthalpy for free water on $\mathrm{KOH}$ concentration in aqueous $\mathrm{KOH}$ solution. 

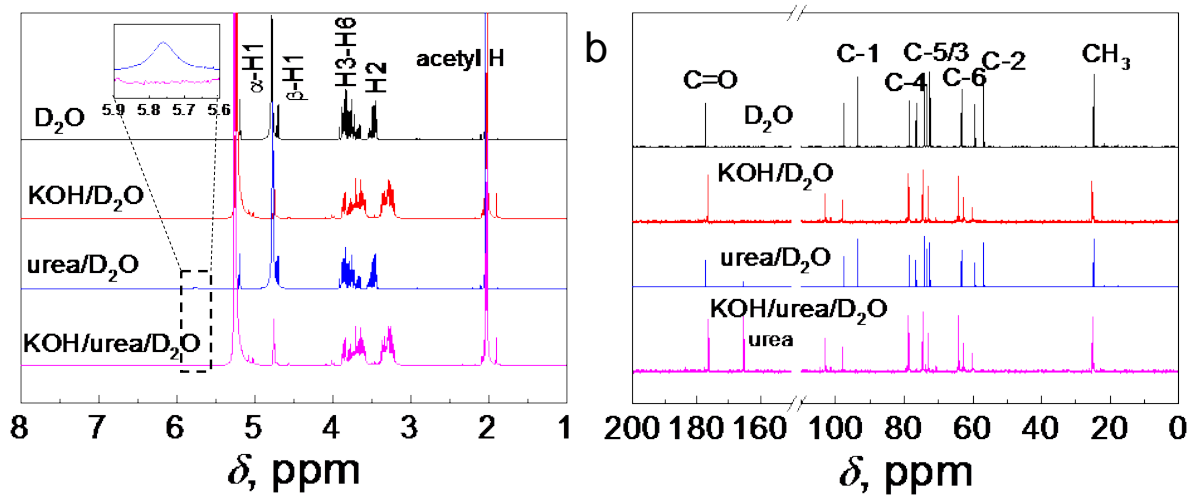

Figure S12. (a) ${ }^{1} \mathrm{H}$, and (b) ${ }^{13} \mathrm{C}$ NMR spectra of GlcNAc in $\mathrm{D}_{2} \mathrm{O}, \mathrm{KOH} / \mathrm{D}_{2} \mathrm{O}$, urea/ $\mathrm{D}_{2} \mathrm{O}$ and $\mathrm{KOH} / \mathrm{urea} / \mathrm{D}_{2} \mathrm{O}$ solutions. The insert is the ${ }^{1} \mathrm{H}$ NMR spectra of amide proton of urea in urea/ $\mathrm{D}_{2} \mathrm{O}$ and $\mathrm{KOH} / \mathrm{urea} / \mathrm{D}_{2} \mathrm{O}$ solutions. 

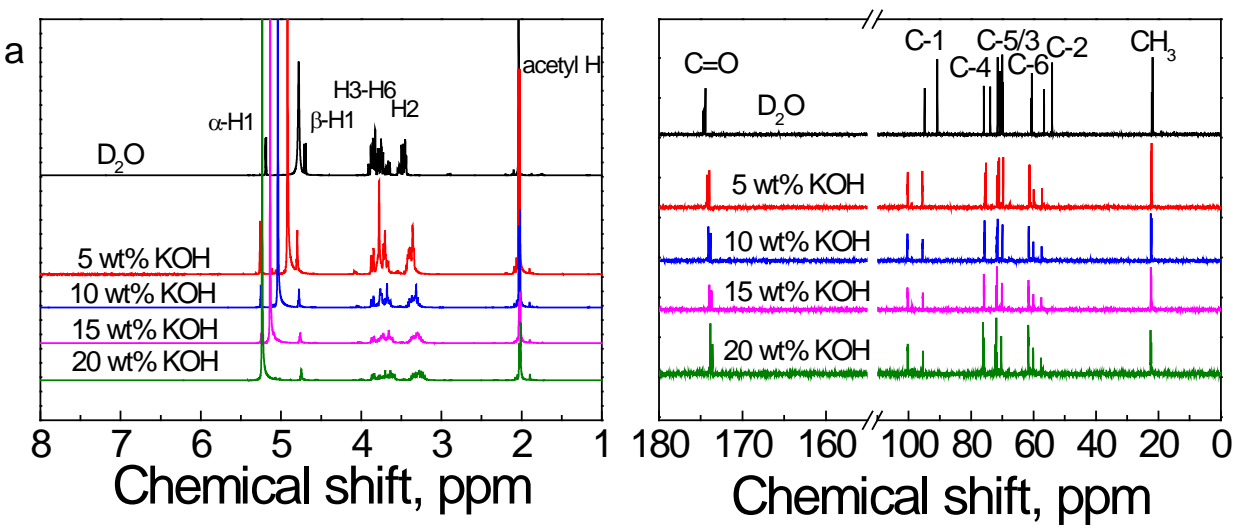

Figure S13. (a) ${ }^{1} \mathrm{H}$, and (b) ${ }^{13} \mathrm{C}$ NMR spectra of GlcNAc dissolved in $\mathrm{D}_{2} \mathrm{O}$ and $\mathrm{KOH} / \mathrm{D}_{2} \mathrm{O}$ solutions with different $\mathrm{KOH}$ concentrations. 

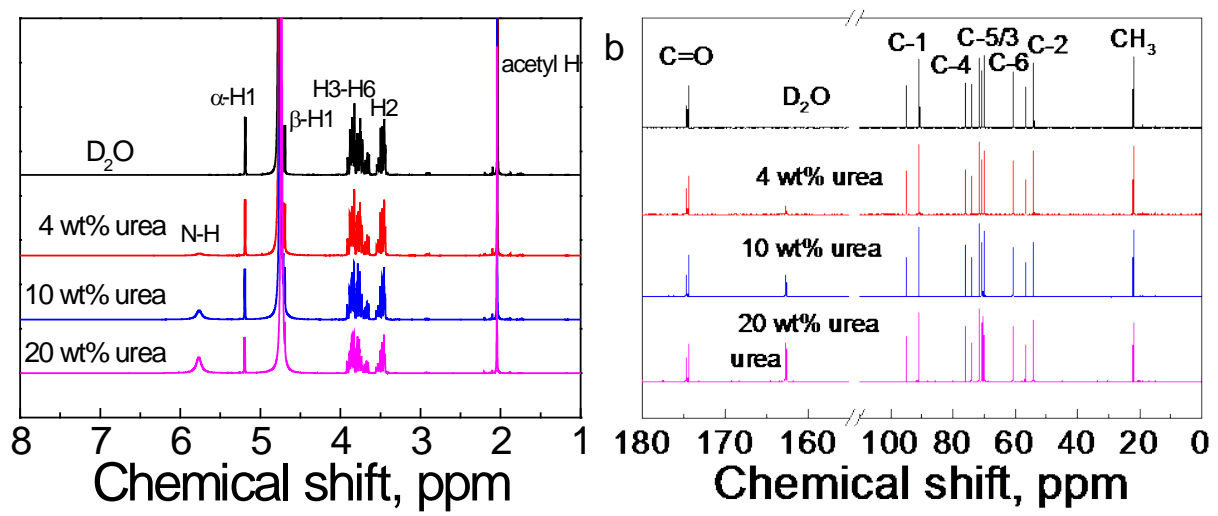

Figure S14. (a) ${ }^{1} \mathrm{H}$, and (b) ${ }^{13} \mathrm{C}$ NMR spectra of GlcNAc dissolved in $\mathrm{D}_{2} \mathrm{O}$ and urea/ $\mathrm{D}_{2} \mathrm{O}$ solutions with different urea concentrations. 

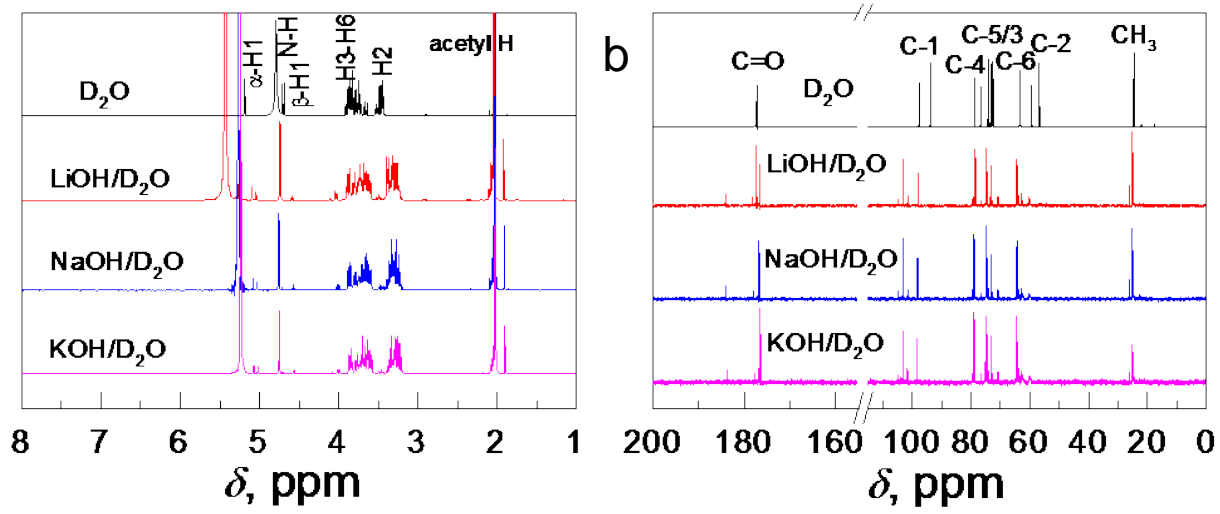

Figure S15. (a) ${ }^{1} \mathrm{H}$, and (b) ${ }^{13} \mathrm{CNMR}$ spectra of GlcNAc in $\mathrm{D}_{2} \mathrm{O}, \mathrm{LiOH} / \mathrm{D}_{2} \mathrm{O}$, $\mathrm{NaOH} / \mathrm{D}_{2} \mathrm{O}$ and $\mathrm{KOH} / \mathrm{D}_{2} \mathrm{O}$ solutions. 


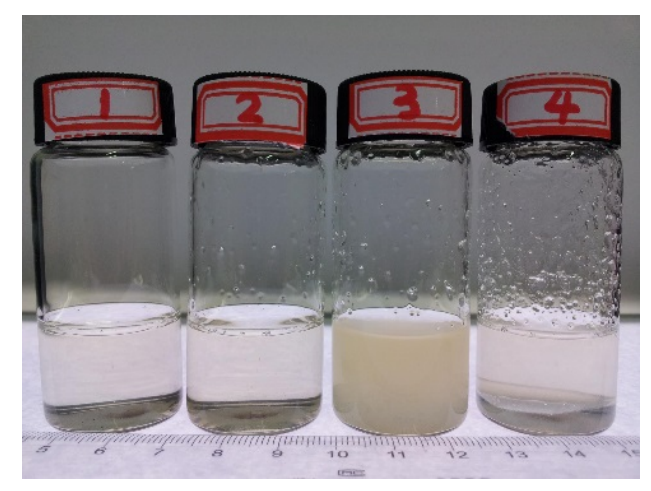

Figure S16. From left to right: Photographs of the $\alpha$-chitin dissolved in aqueous $\mathrm{KOH}$ solution (sample 1), and with addition of 12-Crown-4 (sample 2), 15-Crown-5 (sample 3) and 18-Crown-6 (sample 4), respectively. The molar ratio of the crown ethers to $\mathrm{KOH}$ is $1: 10$. Specifically, the $15-$ Crown-5 is slightly soluble in water. 